\section{Pablo De Santis y el policial en la historieta: teoría y práctica}

Hernán Maltz
Hernán Maltz

Doctorando en el área de Literatura y Licenciado en Sociología, ambos por la Universidad de Buenos Aires. Se desempeña como becario doctoral del Consejo Nacional de Investigaciones Científicas y Técnicas, con lugar de trabajo en el Instituto de Filología y Literaturas Hispánicas "Dr. Amado Alonso" de la Universidad de Buenos Aires, y como docente en las asignaturas Sociología del Arte (Universidad de Buenos Aires) y Sociología del Control Penal (Escuela Penitenciaria de la Nación / Universidad Nacional de Lomas de Zamora). Integra proyectos de investigación sobre el género policial en la Argentina. Contato: hermaltz@gmail.com

Recebido em: 04 de agosto de 2017

Aceito em: 10 de setembro de 2017 
Palabras Clave: Pablo De Resumen: Proponemos una lectura sobre los modos en que el género Santis; Historieta; Género policial se presenta en las historietas y los ensayos sobre historietas policial; Narrativa argentina

KEYwords: Pablo De Santis; de Pablo De Santis. En primer lugar, planteamos una hipótesis para unir sus producciones de historietas con su literatura "para adultos", basada en dos argumentos: por un lado, el género policial une ambas narrativas pero, por otro, se diferencian en que la literatura se sirve más del policial clásico de enigma, mientras que la historieta se aproxima al policial negro. En segundo lugar, repasamos algunos aspectos de las teorizaciones de De Santis sobre la historieta, principalmente en relación al policial negro, a la preeminencia del ámbito urbano y a la pregunta sobre cómo hacer un policial nacional. Finalmente, de acuerdo con nuestra hipótesis sobre el eje policial, analizamos su práctica de guionista en dos libros de historietas publicados en 2016: Justicia poética y Cobalto.

Comics; Detective Fiction;

Abstract: I propose an interpretation based on the ways in which Argentinian narrative detective fiction is presented and represented in comics and essays by Pablo De Santis. In the first place, I maintain an hypothesis that allows to unite his comic and essays's productions with his "adult" literature, based on two arguments: on the one hand, the detective fiction genre unites the two narratives; on the other, they differ in the fact that his literature is closer to the classic detective fiction, while his comics tend to approach the hard-boiled fiction. Secondly, I review some of De Santis's theories about comics, mainly those linked with the hard-boiled fiction, the preeminence of the urban environment and the question of how to make a national detective literature. Finally, according to my hypothesis on detective fiction, I analyze his scriptwriting practice in two comic books published in 2016: Justicia poética y Cobalto. 


\section{UNA HIPÓTESIS: LITERATURA CON POLICIAL CLÁSICO E HISTORIETA CON POLICIAL NEGRO}

Si bien en la actualidad es mayormente conocido como escritor, Pablo De Santis tuvo un inicio profesional como guionista de historietas, hecho que aún es marcado por las pequeñas biografías en las solapas y contratapas de sus libros — que, en una primera oración, tienden a usar tres componentes: guionista, periodista y escritor-. No solo practicó este oficio desde mediados de la década de 1980, en la revista Fierro, cuando ganó el concurso "Fierro busca dos manos" y fue puesto a trabajar junto al otro ganador del certamen, el dibujante Max Cachimba (Juan Pablo González). Posteriormente, con la acumulación de sus lecturas y escrituras, incursionó en la teorización y el ensayo, del que surgieron los libros Historieta y politica en los '80. La Argentina ilustrada (1992) analiza las producciones nacionales de una "década larga" que fija a partir de la desaparición de Héctor Oesterheld en 1977 y de sus últimas producciones. Rico Tipo y las chicas de Divito (1994) es un libro en que repasa los usos del humor, los personajes habituales y las representaciones de las mujeres en la revista Rico Tipo de José Antonio Guillermo Divito. La historieta en la edad de la razón (1998), proyecto más ambicioso en que aborda distintos problemas de la historieta moderna, mundial y nacional, desde la década de 1960. Además de estos libros, cuenta con varios ensayos breves, en gran medida publicados como introducciones a libros de historietas: "El comisario y el león” (1998) — prólogo a Evaristo de Sampayo y Solano López, en la edición de la colección Sobrevivientes de la editorial Colihue-, "Hotel Insomnio" (2010) — prólogo a su obra El hipnotizador-y “Carlos 
Sampayo y el león perdido" (2016a), así como cuatro textos, publicados entre 2004 y 2007, en tomos de las colecciones Biblioteca Clarín de la Historieta y Nueva Biblioteca Clarín de la Historieta, entre los que se hallan "La constancia del viajero" — prólogo a El corto maltés de Hugo Pratt-, "Películas imposibles y mujeres perfectas" — prólogo a Viaje a Tulum y otras historias de Milo Manara-, "Los arquetipos de la risa" — prólogo a Leyendas del cómic argentino, que recopila trabajos de Divito y Lino Palacio- y "La fuga y otras costumbres" - prólogo a Las puertitas del Sr. López de Carlos Trillo y Horacio Altuna-.

Con su mayor énfasis en la literatura, durante varios años De Santis dejó de lado los guiones de historietas, aunque esta afirmación podría ser morigerada, sin ir más lejos, teniendo en cuenta los textos ensayísticos recién mencionados: entre 1992 y 2016, siempre encontró momentos para reflexionar sobre las historietas, aun cuando fuera por encargos de proyectos editoriales y/o teóricos de otros e incluso para trabajar con guiones de ficción, tal como sucede con su rol de adaptador de la novela La ciudad ausente de Piglia a su versión gráfica. De todos modos, en los últimos años volvió con nuevas publicaciones de ficción: El hipnotizador (2010) —dibujada por Juan Sáenz Valiente y convertida en serie televisiva de la cadena HBO en 2015-, El verdadero negocio del señor Trapani (2012) con ilustraciones de Hernán Cañellas-, Justicia poética (2016) -dibujada por Frank Arbelo- y Cobalto (2016) —nuevamente en dupla con Juan Sáenz Valiente-. (Estos libros se suman a Rompecabezas, libro publicado 
a mediados de la década de 1990 y en que se reunían trabajos realizados junto a Max Cachimba en Fierro.)

Aquí planteamos una hipótesis para unir sus producciones de historietas con su literatura "para adultos", hipótesis basada en un doble argumento que las aproxima y, a la vez, las distancia: por un lado, sostenemos que el género policial une ambas narrativas pero, por otro, ellas se diferencian en que la literatura se sirve más del policial clásico de enigma, mientras que la historieta se aproxima al policial negro. ${ }^{1}$

La literatura policial de De Santis es usualmente catalogada como deudora de la vertiente clásica o de enigma (Gamerro, 2006). En esta línea se inscriben novelas como Filosofía y Letras (1998), La traducción (1998) y, especialmente, el homenaje a la narrativa de detectives realizado en El enigma de París (2007) y Crimenes y jardines (2013) —esta última es la que más se acerca a un típico policial inglés, con un sistema de pistas que, al final, apunta a un único culpable, señalado por el detective ante el resto de los personajes, reunidos en una mansión para dicha develación-. $\mathrm{Al}$ contrario, en sus producciones de guiones de historietas tienden a

1 El empleo de los verbos "servirse" y "aproximarse" nos permite recordar una concepción no esencialista de los géneros, para la cual tomamos, entre otras, la distinción de Altman (2000) entre aspectos sintácticos y semánticos, así como la preferencia de Derrida (1980) por la idea de las participaciones genéricas antes que las pertenencias. Por otra parte, de igual manera aquí ligamos la literatura "para adultos" de De Santis con su producción historietística, igualmente podríamos sugerir otro vínculo entre esta última y sus obras clasificadas como propias de la literatura infantil y juvenil, centrado en un factor común que gravita, en mayor medida, en torno al género de aventuras__ además del evidente hecho de que la mayoría de sus obras de este tipo de literatura contienen imágenes, por lo que, desde el punto de vista del soporte utilizado, ambos tipos de producciones usan imágenes y palabras, aunque, por supuesto, con distintas jerarquías-. 
preponderar la acción, la violencia y, como protagonistas, personajes más asociables al private eye norteamericano antes que al armchair detective anglosajón. Los dos libros de historietas publicados en 2016, Justicia poética y Cobalto, poseen personajes que, en efecto, salen al mundo a ejercer violencia y generar muertes, aun cuando sea con el noble fin de restablecer cierto tipo de justicia. A su vez, a diferencia de Julio Fux y Cobalto (protagonistas de Justicia poética y Cobalto, respectivamente), los investigadores de las novelas policiales no causan muertes, sino que, más bien, intentan explicarlas, tal como sucede con Miguel De Blast en $\mathrm{La}$ traducción o con Sigmundo Salvatrio en El enigma de París y Crímenes y jardines.

Además, podemos apreciar en De Santis una práctica literaria que tiene un fuerte arraigo en la disposición de personajes en lugares; es decir, el espacio es un elemento constitutivo de sus narraciones, tal como sucede con el edificio de la facultad en Filosofía y Letras y el Hotel del Faro en La traducción o, en una escala mayor, las decimonónicas París y Buenos Aires en El enigma de París y Crímenes y jardines. Tanto los edificios como las ciudades son elementos muy significativos en la literatura de De Santis (y no solo en sus policiales, sino en toda su obra, si pensamos, por ejemplo, en La sexta lámpara o en Enciclopedia en la hoguera) y, desde luego, no resulta desatinado concebir un probable vínculo entre esta poética literaria y sus inicios en el ámbito de la historieta, en que, justamente, la elaboración de guiones debía contemplar la narración en y del espacio. 
En los dos apartados que siguen ampliamos estas ideas: por una parte, repasamos algunos aspectos de las teorizaciones de De Santis sobre la historieta, principalmente en relación al policial negro, a la preeminencia del ámbito urbano y a la pregunta sobre cómo hacer un policial nacional; por otra, de acuerdo con nuestra hipótesis sobre el eje policial, analizamos su práctica de guionista en los dos libros de historietas publicados en 2016: Justicia poética y Cobalto.

\section{TEORÍA: GÉNERO NEGRO, ÁmBiTO URBANO Y POLICIAL NACIONAL}

El propio De Santis posiblemente estaría de acuerdo con nuestra conceptualización, al menos en el sentido de vincular la historieta en general, tanto como sus guiones en particular, a la hard-boiled fiction. Esto es lo que sostiene, efectivamente, en un ensayo reciente a propósito de la obra historietística y literaria de Carlos Sampayo, a quien emplea como caso ilustrativo de una cuestión que, según confiesa, siempre le resultó llamativa: "la historieta policial reflejó pocas veces el relato de enigma, y sin mayor fortuna. Siempre prefirió el género negro" (De Santis, 2016a, 139). El autor halla la explicación a esto en un factor común sustantivo:

Creo que la explicación a esta preferencia hay que buscarla en aquello que tienen en común el género negro y la historieta: la ciudad. Sé que muchas historietas se apartan de la ciudad (todos los western, muchos relatos de horror, las aventuras marinas de Corto Maltés). Pero a pesar de eso, la ciudad es el escenario esencial de la historieta. La obra de Carlos Sampayo es perfecto ejemplo de esta atracción. (2016a, 139) 


\section{Para argumentar el caso particular de Sampayo, De Santis apunta:}

Alack Sinner y Evaristo (las dos historietas fundamentales de Sampayo, la primera dibujada por José Muñoz, la segunda por Francisco Solano López) no solo transcurren en ciudades, sino que las historias son mecanismos para que las ciudades aparezcan como universos cerrados. Los dos dibujantes trazan con maestría el retrato de Nueva York o de Buenos Aires en el momento en que estas se niegan a ser escenarios, y buscan convertirse en protagonistas y adueñarse de la trama. Muñoz lo hace a través de las voces múltiples de la ciudad, que aparecen en palabras pronunciadas al pasar, carteles pegados a las paredes, una caligrafía donde texto y dibujo se confunden. (La apoteosis de la ciudad como texto aparece en una página donde las palabras forman edificios). Solano López, en cambio, trabaja con los recuerdos, con una ciudad que se sabe fugaz, víctima incesante del cambio. (2016a, 139)

Pero, a su vez, hay un fuerte vínculo con el policial que no pasa por la ciudad, sino por el protagonista de las historias. Respecto a Evaristo, De Santis sostiene:

Sampayo tiene la audacia de tomar la figura de un policía. La literatura policial argentina (y sobre todo después de la dictadura militar) le ha escapado al policía, imposible de asimilar con la idea del héroe. Evaristo es honrado y rechaza la tortura, pero está mostrado sin una mirada edulcorada: le pega a una mujer, no le incomodan demasiado los interrogatorios a los golpes. Si se le hiciera un test de personaje políticamente correcto, no aprobaría [...]. Pero encarna, en ese universo sórdido, una aspiración al bien. (2016a, 140) 
La preocupación por la configuración de un policial nacional en Evaristo ya se encuentra en su libro ensayístico de 1992, Historieta y politica en los '80. La Argentina ilustrada, donde consigna:

Una de las mejores historietas de esta [primera] etapa de Fierro fue "Evaristo" [...]. Trabajaba a partir de un problema político y estético que más de un escritor se ha planteado: ¿Cómo escribir policiales en la Argentina? Si la figura ideal del policial es el detective privado o la policía, ¿cómo construir un héroe en un país donde los private eye o son increíbles o son meros alcahuetes, y la barbarie policial es impresentable como heroísmo?

La respuesta: viajar al pasado. El guionista busca a un personaje real pero legendario: Evaristo Meneses [...].

Sampayo construye a un héroe duro pero no implacable. Para no escaparle a algunos temas lo hace detener una escena de tortura. ¿Por qué el Buenos Aires de los 30 ó 40? Para que sea un mundo lo suficientemente alejado, para que se vuelva mítico (De Santis, 1992, 37-38)

Con la última reflexión sobre el espacio, vemos que la construcción y concepción del personaje es pensada de manera indisociable con respecto al lugar donde se desarrolla la acción.

La cita anterior nos devuelve, asimismo, al problema de los géneros, en tanto constituye otro componente sustantivo de la reflexión de De Santis sobre la historieta. Así lo apreciamos, por ejemplo, en "Hotel Insomnio", el breve texto que antecede las historias de El hipnotizador y donde reflexiona sobre un nivel más general de las ficciones, en vínculo con el policial y el fantástico: 
Todo relato cuenta el momento en que el presente se enfrenta al pasado. Si gana el pasado, la historia tendrá un matiz trágico o melancólico. Si gana el presente, el tono probablemente será irónico. En una historia policial, por ejemplo, es el pasado de los personajes, algo al principio invisible, lo que explica el crimen. La resolución del crimen significa la superación del pasado, y por eso los lectores llegamos a la última página de una novela policial con una sonrisa. En los relatos fantásticos, el pasado (que aparece bajo la figura de un fantasma, alguna antigua tradición, un objeto mágico) no termina de resolverse nunca. De allí que el tono sea fatalista, quizás melancólico. (De Santis, 2012 [2010], 7)

Por lo tanto, en las formulaciones de De Santis hallamos que la reflexión sobre la historieta acarrea pensar igualmente el problema de los géneros. Además, así como piensa el policial en la historieta, en el ensayo "Crímenes ilustrados” (2006) se preocupa por la parte gráfica de la literatura policial, cuyos "umbrales" (Genette, 2001), dados por tapas, contratapas y otras mediaciones que anteceden al texto propiamente dicho, colaboran con la definición del género: “¿Dónde empiezan los libros? No exactamente en la primera página, porque antes está el título y el dibujo de la portada y el texto de contratapa y el diseño de la colección. Todos estos elementos tienen la función de hacer una serie de promesas con respecto al texto que el lector va a leer" (De Santis, 2006, 51). Incluso los colores poseen un significado particular en el caso de la narrativa policial:

Los colores del policial han sido tradicionalmente dos: el negro y el amarillo. En Italia se identifica a los policiales con este último, hasta el punto que la palabra para novela policial es «giallo». En Francia, el negro, a causa de la famosa Série Noir de la editorial Gallimard. Tor eligió para sus 
tapas el amarillo; El séptimo círculo evitó la definición por color, que aludía a una literatura más barata. La editorial Hachette agregó un nuevo color al espectro del policial: creó en los años ' 50 la Serie naranja. (2006, 52-53)

De Santis también dedica una mención especial a la colección Rastros, de la Editorial Acme, y sus portadas que podríamos ubicar en las antípodas al diseño abstracto y discreto de El séptimo círculo:

Otra de las colecciones que lideró el mercado durante los años ‘ 40 y ' 50 fue Rastros, dedicada a publicar la novela dura norteamericana. Allí estaba, por ejemplo, Cosecha roja, de Dashiell Hammet, considerada la primera novela negra. Rastros era una colección económica que repetía los procedimientos de las pulp fiction norteamericanas. No había ningún intento de darle prestigio al género y las portadas testimoniaban ese desinterés. En Rastros se elegían en general escenas de la trama, con especial atención al asesinato y a las mujeres. Sexo, crimen y dinero, tres elementos claves del policial. El dinero nunca puede ser adecuadamente representado, pero el crimen y el sexo, en cambio, sí. A diferencia de los libros de Tor, aquí el ilustrador, si bien probablemente no había leído el libro, al menos tenía una idea de la trama, y podía dibujar una escena de la novela sin que estuviera aludida por el título. $(2006,53)$

Con el ejemplo de Rastros, observamos claramente cómo a De Santis le interesa la parte gráfica de los umbrales de la literatura policial. Parte gráfica que incluso es homenajeada en su literatura, por ejemplo, cuando en La traducción se hace referencia a la portada de una novela que debía traducir el uruguayo Vázquez, Una lagartija en la noche, de la que dicho traductor pierde su ejemplar e inventa la historia a partir de la portada y la contratapa: “QQué dibujo lleva la tapa?, pregunto. Un enmascarado le clava 
un puñal a una pelirroja. La empuñadura tiene forma de lagartija. ¿¿Dice la contratapa dónde transcurre la acción? En Nueva York. Pasé toda la noche traduciendo el original perdido" (De Santis, 1998a, 33). Pero, además, en "Crímenes ilustrados" De Santis vuelve de manera clara a pensar una idea sustantiva sobre el concepto de género:

Este modo en que los libros «empiezan antes de empezar» es más acentuado en la literatura de género. Los géneros - la ciencia ficción, el policial, la literatura de terror, etc. — son máquinas de esperar. El lector siempre tiene expectativas sobre un libro, pero cuando se trata de literatura de género, esas expectativas están codificadas y organizadas. Si se trata de la literatura de horror, esperamos la irrupción de lo fantástico y lo terrible, aunque el texto comience con un amable almuerzo campestre. Si se trata de literatura policial, aguardamos el crimen, la investigación, las revelaciones parciales y engañosas, la verdad final. El texto de contratapa, la ilustración y la índole de la colección nos anuncian cuál es el primer horizonte de lectura, cuál es la tradición a la que el autor ha de aportar, con mayor o menor talento o suerte, sus propias variantes. $(2006,52)$

En efecto, vemos que el autor tiene muy presente, en un nivel conceptual, los modelos genéricos. A continuación pasamos al análisis de dos historietas en las que, en buena medida, observamos una construcción que se sirve de manera significativa de una matriz genérica específica: el policial negro.

\section{Práctica: Julio Fux y Cobalto, dos "tipos duros" (pero no simples)}

La afirmación de De Santis sobre el hecho de que la narrativa gráfica "[s] iempre prefirió el género negro" (2016a,139) puede ser usada para analizar una clave significativa de los dos libros de historietas que publicó en 2016: 
Justicia poética y Cobalto —el primero dibujado por Frank Arbelo y el segundo por Juan Sáenz Valiente-. En ambos hallamos varios elementos propios del policial negro: protagonistas construidos a lo private eye, historias ambientadas en zonas urbanas — que son elementos esenciales de las ficciones-y cierto tipo de criminalidad "social" — delitos económicos, sobornos, estafas, lavado de dinero, etcétera-.

Las dos aventuras gráficas, en esencia, pueden ser resumidas de la siguiente manera: una figura heroica sale a matar a "los malos". Justicia poética consta de nueve casos en los que el escritor Julio Fux se encarga de matar o hacer que mueran personajes que quedan identificados como malvados. Cobalto, más breve, se compone de cuatro capítulos en que el héroe que da título a la historia tiene a su cargo la misión de buscar y acabar con los responsables de cierto "mal urbano" que, desde un principio, se nos presenta de manera difusa.

Tanto Julio Fux como Cobalto son representados como hombres maduros y solitarios, "tipos duros" que buscan la paz a través de la violencia de los puños y las armas - las portadas de ambos libros los retratan portando un rifle y una pistola, respectivamente-. Son personajes íntegros en un mundo que no lo es, tal como lo era el prototipo de detective concebido por Chandler (1970) en "El simple arte de matar"; apelan a la violencia física para un fin noble: una voluntad y una búsqueda de justicia, aunque, en un caso, el de Fux, la motivación sea personal y las acciones realizadas 
por iniciativa propia, ${ }^{2}$ mientras que en el otro existe una obligación externa e incluso cierta reticencia inicial para corresponder el trabajo por encargo, cuando Cobalto protesta ante Cobre: "¿Por qué yo? ¿No hay otros más jóvenes, más capaces?" (2016c, 15), a lo que el mensajero responde: "El señor Zinc dice que usted es el mejor. Que se necesitan las habilidades de la vieja escuela" (2016c, 15). Para Cobalto se trata, sin dudas, de una obligación: “¿Cuándo es el trabajo?” (2016c, 17), pregunta a Cobre, y este responde: “¿'El' trabajo? Los trabajos, querrá decir” (2016c, 17). Cobalto se sorprende: “¿Cuántos son?” (2016c, 17), ante lo que su interlocutor dice: "Cuatro. Mañana le llegará el primer nombre" (2016c, 17). A partir de esta caracterización, podríamos vincular con mayor énfasis a Cobalto con el agente de La Continental de Dashiell Hammett, en tanto que Fux sí se hallaría, de manera más pura, en la estela de Marlowe.

Más allá de ciertos matices, ambos personajes están construidos en estrecho vínculo con el private eye norteamericano. Heroicos y seguros de sí mismos, con amplias destrezas físicas, contrastan con los antihéroes que protagonizan las novelas policiales de De Santis, individuos también masculinos pero que suelen ser inexpertos, dubitativos y/o débiles corporalmente: Miguel De Blast con sus crónicos dolores de cabeza,

2 En el tercer capítulo, "La enfermera del turno de la noche", apreciamos claramente que la obligación de Fux es autoimpuesta: "Quisiera olvidarme de Sonia Vidart. Dejar que siga visitando viejos y enfermos, con sus leves pasos nocturnos. Pero siento al cíclope conmigo. Todo se hace claro y brillante. Mi vida deja de estar vacía. Tengo una misión” (2016b, 32). (El Cíclope es una creación de la subjetividad de Fux, que lo acompaña desde la niñez y lo impele a actuar en busca de justicia; también El cíclope es un libro de su autoría.) 
Esteban Miró con sus inseguridades que apenas le permiten alcanzar la adultez o Sigmundo Salvatrio y su desarrollo profesional a la sombra del detective Craig. Estos tres tienden a dar una imagen cómica de sí mismos; por ejemplo, interpelado por el cazador Clemm - “Le gusta cazar?” —, Salvatrio contesta: "A los diez años con una honda le tiré una piedra a un pajarito, pero le erré" (De Santis, 2013, 60). ${ }^{3}$

De todas formas, aún en sus caracterizaciones como tough guys, tanto Fux como Cobalto presentan una mayor complejidad, más acentuada incluso en el caso del primero. No olvidemos que Fux es poeta e ingeniero; lo cual nos permite evocar al criminal de Poe en "Los crímenes de la calle Morgue", que es matemático y poeta a la vez- y que incluso cuenta con saberes médicos, para lograr la muerte de la enfermera Vidart, le inyecta "una dosis masiva de antitrombina, un inhibidor de la coagulación” (2016b, 36). Su faceta poética y literaria se demuestra con referencias explícitas: Borges y Coleridge, además de nombres como Rubén Darío, José Asunción Silva y Manuel Gutiérrez Nájera, a quienes confiesa haber leído desde su infancia. Particularmente, Fux lee y plagia, y reconoce abiertamente que lo hace (2016b, 10 y 37), a Edgar Lee Masters y su Spoon River Anthology, aunque cambia epitafios de muertes ficcionales por muertes reales: "La musa de Masters era la muerte imaginaria. La mía, la muerte real” $(2016 b, 37){ }^{4}$

3 Tales personajes son la norma de su literatura, pero hay excepciones, como sucede con el protagonista de los libros Lucas Lenz y el Museo del Universo y Lucas Lenz y la mano del emperador, que es construido en mayor afinidad con el prototipo de detective norteamericano.

4 En este sentido, observamos una nítida analogía entre las estructuras narrativas de Filosofía y Letras y Justicia poética. En la primera, Brocca pretende escribir una novela que intervenga en 
Se reconoce como intelectual; tanto cuando piensa de manera jocosa en "la misión social" (2016b, 55) de esta figura, como cuando da una pista sobre su formación: "A veces dedico toda la semana a leer a un mismo autor. Otras veces un tema. Esta vez es la arquitectura" (2016b, 15). Si bien en un principio es descripto por Elena, su empleada doméstica, como un ogro, posteriormente se nos revela su capacidad de seducción, no mostrada desde un primer momento, pero gracias a la que finalmente se vincula sexualmente con Lía, una profesora de literatura que lo había invitado a participar de unas jornadas de poesía (y tampoco olvidemos que en su vínculo con Mariana también apreciamos una tensión sexual; de hecho, en un cuadro casi del final de la historieta, vemos la sorpresa de Mariana al ver dentro de un café a Fux y Lía).

En cuanto a Cobalto, se trata de un farmacéutico ya entrado en años, pero muy corpulento y voluminoso, solitario y con Míster Cat como su única compañía doméstica (ámbito donde se distiende con música). Su tiempo de ocio queda asociado al ajedrez, juego que practica con Zinc dos veces en la historia: una en sus recuerdos de juventud, la otra en el final de su misión. En el prólogo del libro, en un breve texto de presentación, leemos otro aspecto que hace a la especificidad de Cobalto:

la realidad, y así da curso a su Filosofía y Letras. De manera similar, en el caso de Julio Fux, las muertes que genera son la fuente de inspiración para escribir los epitafios que componen su Justicia poética: "Yo siempre necesité de la vida real [para escribir]" (2016b, 20), le confiesa a Mariana. En ambas ficciones, como vemos, los personajes escriben un libro homónimo respecto a la publicación real de De Santis. 
La escasez de cobalto en la naturaleza sirve para reforzar el carácter especial del protagonista (acompańado de secundarios como Zinc y Cobre), pero este metal se erige además en inspiración cromática del apartado visual de la historieta. Los tonos cobalto tiñen con sus matices la mencionada oscuridad y habilitan un ambiguo juego con el concepto griego de phármakon ("remedio" y "veneno" a la vez), ya que el cobalto puede tener usos medicinales o efectos nocivos. (Martignone, 2016, 4)

Si bien el influjo de la hard-boiled fiction se centra de manera sustantiva en la configuración del protagonista —recordemos, a propósito del famoso ensayo ya citado de Chandler, que en el final de dicho texto se dedica a describir los rasgos modélicos de su protagonista-, ya hemos mencionado la importancia del ámbito urbano. A propósito de los clásicos norteamericanos, no olvidemos el estatuto preponderante de la ciudad en Cosecha roja de Dashiell Hammett, en la que el protagonista viaja hasta Personville, que es popularmente conocida como Poisonville, es decir, "ciudad venenosa" (1962, 17). Exactamente la misma carga semántica encontramos en Cobalto: "Porque todo está contaminado, envenenado" (2016c, 19), dice el protagonista, en una sentencia en donde "todo" implica sustantivamente a la ciudad, que es todo: espacio de la acción y ámbito de la totalidad de la vida de la ficción — recordemos la "ciudad-país" a la que apela De Santis en sus conceptualizaciones (1998b, 75) —, lugar a

5 A su vez, teniendo en cuenta que el guionista es De Santis, tampoco debemos descartar otro posible sentido del vocablo "cobalto", que era el nombre de una de las colecciones de la popular editorial Acme, a mediados del siglo XX. 
defender y a disputar en la práctica, pero igualmente motivo de reflexiones conceptuales por parte de los personajes.

Desde el comienzo, la ciudad es caracterizada como peligrosa, cuando Cobalto deja su trabajo en la farmacia y nos comunica: "Tengo que caminar diez cuadras hasta mi casa. En esta ciudad ya nadie camina después del atardecer. Pero a mí me cuesta dejar las viejas costumbres" (2016c, 9). En la secuencia sucedánea, dos hombres se aproximan a él y lo atacan en el parque. Cobalto se deshace de ellos y, al día siguiente, cuando su asistente Darío le indica una visita más temprana de la policía a la farmacia, contesta: "No van a volver. Nunca vuelven. En esta ciudad, investigación y amnesia son dos palabras que significan lo mismo" (2016c, 13). Con esta afirmación, no solo asociamos la institución policial a la ineficiencia, sino que apreciamos que el orden social, que se corresponde con el orden urbano, se encuentra alterado. Luego Cobre arriba a la farmacia y plantea la necesidad de que Cobalto intervenga, convocado con premura por Zinc. “¿De qué se trata esta vez?” (2016c, 15), pregunta el protagonista, a lo que Cobre responde: "De la oscuridad" (2016c, 15). Y amplía:

¿No ha notado cómo la ciudad está más oscura cada día? Es el reino de las tinieblas. Las familias con niños se marchan. Los jóvenes se marchan [...]. Quedan los viejos, los que no se pueden ir [...]. Casas abandonadas [...]. Edificios vacíos. Es como si hubieran envenenado a la ciudad entera con pociones de oscuridad [...]. La tasa de suicidios creció un 25 por ciento en los últimos meses. La violencia... usted lo ha visto, ayer mismo. (2016c, 16) 
Ante este panorama, Cobalto pregunta: "¿Y qué se puede hacer contra esa oscuridad?" (2016c, 16), ante lo que Cobre responde: "Aplicar un antídoto llamado Cobalto” (2016c, 16).

Morand, uno de los cuatro "individuos-alga" (o "tatuados", como se los denomina en la propia ficción), desafía al protagonista: "Somos los dueños de la ciudad. Somos los muertos" (2016c, 27). ${ }^{6}$ Después de acabar con él, Cobalto habla con Cobre, quien advierte: "Las algas tienen su propia idea de lo que debe ser esta ciudad... y el mundo" (2016c, 30), y con esta afirmación corroboramos que hay una incuestionable identidad entre ciudad y universo. Cobre le nombra a Cobalto su siguiente objetivo, Madame Ormuz. Ante el reparo del protagonista, quien dice nunca haber matado a una mujer, Cobre responde: "No es una mujer. Es un monstruo. Es la arquitecta de la ciudad... la que ha convertido esto en torres y ruinas" (2016c, 30). Luego, en palabras de la propia Ormuz, tenemos una descripción de lo que sería la continuación de su proyecto de ciudad: "Haré puentes entre las torres, para no tener que pisar jamás el suelo maldito [...]. Y una bóveda cerrará los cielos y siempre será de noche [...]. No habrá cementerios bajo tierra: le entregaremos los cadáveres a los vientos..." (2016c, 36).

La ciudad también aparece como un espacio aciago en Justicia poética, aunque en este caso se trata de una innegable representación de una

6 La presencia de adversarios ominosos que no son humanos nos remite al motivo de la ciudad invadida, propio de la ciencia ficción y que, particularmente en el marco de la historieta argentina, nos devuelve al inevitable antecedente de El eternauta. 
Buenos Aires actual, con un sesgo más realista: Fux menciona los barrios de Palermo y Recoleta, además de que en uno de los cuadros se muestra una entrada de la estación Perú de la línea A de subterráneos porteńos. ${ }^{7}$ Ya desde el comienzo de la historia, la periodista Mariana le confiesa a Fux su decisión de antańo de abandonar su pueblo e ir hacia la gran urbe, a lo que el poeta contesta: "Así que yo la condené a esta ciudad enorme y terrible" (2016b, 10). El empresario Torn también vive el ámbito urbano como su zona de preocupaciones, mientras que lo rural se erige como el espacio y el momento de tranquilidad: "En la ciudad tengo que moverme con custodios. Pero cuando voy a pescar estoy solo por fin" (2016b, 12). Aunque, al final, Fux aprovecha la soledad del campo para asesinarlo en el lago donde pesca.

Por último, otro aspecto significativo de estas historietas lo hallamos en la representación de cierto tipo de criminalidad, de orden, digamos, "social" y más propio del policial negro (clase de criminalidad presente fundamentalmente en Justicia poética y no tanto en Cobalto). En general, en la mayor parte de la narrativa de De Santis, el homicidio es el crimen que se comete y que moviliza las tramas de las historias. Sin embargo, en

7 Desde luego, el vocablo "realista" resulta problemático, pero al menos otorga cierto carácter ordenador. En última instancia, de todas formas, es cierto que en Justicia poética hay una representación de la ciudad que se aproxima más a la ciudad real, frente a la ciudad de Cobalto, que tiende a emplear más elementos góticos y fantásticos, aunque, asimismo, en esta historieta podemos hallar edificaciones, como la farmacia de Cobalto, que nos remiten a la capital argentina, que la invocan de una forma extrañada; e incluso recordemos que, cuando se menciona la historia del doctor Jarman, hay una referencia explícita a la Antártida (2016c, 29) y, a través de esa distancia, a la Argentina. 
los dos primeros casos de Justicia poética, los homicidios que comete Fux son una forma de saldar los crímenes que verdaderamente importan en estas historias, que también son homicidios (muchas veces encubiertos), pero, asimismo, incluyen otro tipo de delitos: en el primer caso, "El altillo", se presenta a Hernando Torn, un empresario aficionado a la pesca, con el siguiente pensamiento: "Hizo peores cosas que matar peces. Lo acusaron por lavado de dinero y otros delitos financieros" (2016b, 9). A estas transgresiones se suman referencias a los homicidios de su secretaria y de su socio, que iban a declarar en su contra, aunque Torn se anticipa y los mata (a la secretaria se la muestra cayendo desde la altura de un edificio, en tanto que otro cuadro de historieta basta para mostrar al socio, muerto en su automóvil con una herida de bala en el entrecejo). En el segundo caso, "El cíclope", la figura del victimario elegido por Fux es otro empresario, en este caso del rubro de la construcción y los negocios inmobiliarios:

Hace tiempo que estudio la carrera de Mario Lavendor. Ha conseguido que lo autoricen a hacer una torre en nuestro barrio, aunque todas las casas son bajas [...]. Su primer edificio, construido en 1990, sufrió un pequeńo inconveniente a los dos años de terminada la obra [en el siguiente cuadro vemos a una mujer cayendo desde un balcón que se viene abajo]. Pero eso no desanimó a Lavendor. Su especialidad consistía en abaratar los costos de los materiales [...]. Ya son cuatro los obreros de la construcción que han perdido la vida en sus accidentes. $\mathrm{Y}$ ahora hasta sus inversores lo han abandonado. (2016b, 17)

En esta historia, para entablar contacto con Lavendor, Fux se presenta como representante de capitales foráneos, puesto que, según el poeta, el 
arquitecto "[e]stá buscando con desesperación inversores del extranjero que necesiten lavar dinero" $(2016 \mathrm{~b}, 18)$. Cuando se juntan en persona, es el propio Fux quien, en su actuación, menciona la proyección de delitos de orden económico: "No soy yo el que invierte, sino la gente a la que represento. Necesitan mover el dinero cuanto antes. Desgraciadamente en toda América Latina hay una legislación absurda que nos impide hacer negocios con libertad" (2016b, 18). En su segundo encuentro, el propio Lavendor menciona otros delitos económicos, vinculados, además, con la complicidad de ciertos sectores políticos: "Construir una torre en una zona de casas no es gratis. Son tantos los funcionarios con los que hay que conversar [...]. Los sobornos nos cuestan el equivalente a dos departamentos de cuatro ambientes" (2016b, 23).

No olvidemos, por cierto, que el cuarto capítulo de Justicia poética, que es el primero en el orden cronológico de la historia fictiva, tal como indica su título: "El primer epitafio", apunta igualmente a la criminalización del mundillo empresarial. Mariana, la joven periodista que entra en contacto con Fux, menciona a Gabriela, la difunta esposa del poeta: "Sé que el que atropelló a su esposa se llamaba Carlos Prasco Pratti. Era uno de esos empresarios que aparecen en las revistas junto a modelos en leve ascenso y actrices en franco descenso. Le encontraron alcohol y cocaína en la sangre, pero quedó libre, a pesar de que tenía otras cuatro causas por accidentes graves" (2016b, 39). El propio Fux completa el panorama: "Prasco tenía antecedentes, es cierto, pero tenía también un padre que era dueńo del estudio jurídico Prasco y Pratti, donde trabajaban unos sesenta abogados" 
(2016b, 39). De este modo, leemos que Carlos Prasco Pratti queda finalmente en libertad, aunque pronto encuentra la muerte en un presunto accidente, que en verdad es develado como homicidio, según Mariana y según el propio Fux, que rememora su accionar.

Sin embargo, la criminalización del ámbito empresarial -entre quienes, además de los ya mencionados, podemos incluir al empresario Ferro Dillman, aunque no aparece sino a través de su voz por teléfono- no es privativa de otras: también tenemos profesionales del mundo de la salud (la enfermera Sonia Vidart y el psiquiatra Adolfo Lumden), del campo artístico (Sebastián Burgos Paz, que responde también a un arquetipo de artista-empresario), del propio mundo de los detectives (Nelson Freytas y su función estructural de mostrar que todo el mundo está corrompido, aún los private eyes) e incluso a un chofer de ómnibus (Héctor Vallés). De este modo, los asesinos pertenecen a distintos estratos sociales, aunque la mayor parte pertenece a, digamos, las clases altas. El propio Fux es un criminal, un homicida en serie, y esto queda claro a través de la intervención de Mariana, que obliga al poeta a contradecir su accionar concreto: "La justicia por mano propia es una cosa abominable" (2016b, 40). El propio Fux, al servirse de la justicia por mano propia, es consciente de su estatuto de loco: "Si de verdad tuviera amigos psiquiatras, me encerrarían en el manicomio" (2016b, 95). Pero, en un orden social corrompido, tal parece la solución más sensata. En este sentido, podemos retomar la definición, por parte de De Santis, del Evaristo de Sampayo y Solano López, y usarla para definir tanto a Fux como a Cobalto: "Si se le hiciera un test de personaje políti- 
camente correcto, no aprobaría [...]. Pero encarna, en ese universo sórdido, una aspiración al bien” (2016a, 140).

\section{REFERENCIAS BBLLIOGRÁFICAS}

Altman, Rick. Los géneros cinematográficos. Barcelona: Paidós, 2000.

Chandler, Raymond. "El simple arte de matar" In: El simple arte de matar. Buenos Aires: Tiempo Contemporáneo, 1970, 187-206.

Dashiell Hammett, Samuel. Cosecha roja. Novelas escogidas. Madrid: Aguilar, 1962.

De Santis, Pablo. Historieta y politica en los '80. La Argentina ilustrada. Buenos Aires: Letra Buena, 1992.

. La traducción. Buenos Aires: Planeta, 1998a.

__. La historieta en la edad de la razón. Buenos Aires: Paidós, 1998b.

- "Crímenes ilustrados" In: La Puerta FBA. Revista de Arte y Diseño, no 2, 2006, 51-55.

. "Hotel Insomnio" In: El hipnotizador. Dibujado por Juan Sáenz Valiente. Buenos Aires: Mondadori, 2012 [2010], 5-7.

. Crímenes y jardines. Buenos Aires: Planeta.

- "Carlos Sampayo y el león perdido". Setton; Román; Gerardo Pignatiello (comps.). Crimen y pesquisa. El género policial en la Argentina (1870-2015): literatura, cine, televisión, historieta y testimonio. Buenos Aires: Título, 2016a. 139-142.

. Justicia poética. Dibujado por Frank Arbelo. Buenos Aires: Colihue, 2016b. . Cobalto. Dibujado por Juan Sáenz Valiente. Buenos Aires: Hotel de las ideas, 2016c. 
Pablo De SANTIS y El POLICIAL EN LA historieta: TEORÍA y PRÁCtica

Derrida, Jacques. "La loi du genre” In : Glyph, no 7, 1980. 176-232. [Traducción al castellano de Ariel Schettini para la cátedra "C" de Teoría y Análisis Literario de la Facultad de Filosofía y Letras de la Universidad de Buenos Aires]

Gamerro, Carlos. "Para una reformulación del género policial argentino" In: El nacimiento de la literatura argentina y otros ensayos. Buenos Aires: Norma, 2006. 79-91.

Genette, Gérard. Umbrales. México D. F.: Siglo Veintiuno, 2001.

Martignone, Hernán. "Remedio para melancólicos”. De Santis; Pablo; Juan Sáenz Valiente, Cobalto. Buenos Aires: Hotel de las ideas, 2016. 3-4. 
